community treatment to be judged in contemporary settings where, in most developed countries, there is reasonable statefunded community care. Len Stein, Mary Test and their colleagues in Wisconsin have made a great contribution to community care by the introduction of PACT but they should not adopt the reflex argument that all studies that show ACT or intensive care programmes to be less effective in other settings must be failing because they do not apply the PACT model properly. The fact is that PACT is primarily a care philosophy backed by a secondary compendium of interventions that have rarely been tested individually. One of its core features, the case-load of only 8-12 per worker, has recently been shown in a much larger trial than any others to be unimportant in influencing outcome (UK700 Group, 1999). There may be many other elements of PACT that are also unimportant. Stein $\&$ Santos (1998) quote our own work (Merson et al, 1992) as indicating that ACT works outside the USA. Our service had case-loads of 20-25 per worker, did not have 24-hour cover and had psychiatrists working full-time in the team, all of which invalidates its description as an ACT model.

The other issue that must be taken account of by ACT enthusiasts is the need for ACT teams to have much closer liaison with existing teams when there is already well-established community care. This was never a problem at the time ACT was originally introduced as there was no competition. Now that there is a backbone of community care present in the UK and many other countries, it is really inappropriate for a new assertive team to come along and indulge in its autonomous activities with a small number of clients without establishing formal links with other teams, both in-patient and outpatient, in the relevant areas. I have drawn attention (Tyrer, 1999) to the similarity between ACT and plant succession in alien habitats; ACT is like a specialised plant that does extremely well in conditions that are alien to community care, but as it improves the circumstances for good care it gradually becomes redundant and can be replaced. This does not mean the principles of ACT are abandoned; it is just that the philosophy of seamless transfer between hospital and community is rarely supported by small teams based in the community with no responsibility for services beyond their immediate clients.
Such teams and their evangelists should really be more humble before they advise others on how to run a comprehensive mental health service.

Gandhi, N., Tyrer, P., Evans, K., et al (2000) A randomised controlled trial of community-oriented and hospital oriented care for discharged psychiatric patients: influence of personality disorder on police contacts. Journal of Personality Disorders, in press.

Marshall, M., Lockwood, A., Gray, A., et al (1998)

Assertive community treatment for people with severe mental disorders. In Schizophrenia Module of the

Cochrane Database Systematic Reviews (eds C. G. Adams, L. Duggan, J. de Jesus Mari, et al). Oxford: Update Software.

_, Bond, G., Stein, L. I., et al (1999) PRiSM Psychosis Study. Design limitations, questionable conclusions. British Journal of Psychiatry, I75, 50I-503.

Merson, S., Tyrer, P., Onyett, S., et al (1992) Early intervention in psychiatric emergencies: a controlled clinical trial. Lancet, 339, |3||-13|4

Sashidharan, S. P., Smyth, M. \& Owen, A. (1999)

PRiSM Psychosis Study. Thro' a glass darkly: a distorted appraisal of community care. British Journal of Psychiatry, I75, 504-507.

Stein, L. I. \& Santos, A. B. (1998) Assertive Community Treatment of Persons with Severe Mental Illness, p. 31. London: WW. Norton.

Thornicroft, G., Becker, T., Holloway, F., et al (1999) Community mental health teams: evidence or belief? British journal of Psychiatry, 175, 508-513.

Tyrer, P. (1999) What is the future of assertive community treatment? Epidemiologia e Psichiatrica Sociale, 8, 16-18

_ , Coid, J., Simmonds, S., et al (1999) Community mental health team management for those with severe mental illness and disordered personality. In Schizophrenia Module of the Cochrane Database Systematic Reviews (eds C. G. Adams, L. Duggan, J. de Jesus Mari et al). Oxford: Update Software.

UK700 Group (1999) Intensive versus standard case management for severe psychotic illness: a randomised trial. Lancet, 353, 2185-2189.

P.Tyrer Division of Neuroscience and Psychological Medicine, Imperial College School of Medicine, St Mary's Campus, Paterson Centre, 20 South Wharf Road, London W2 IPD

\section{Antidepressant choice to minimise treatment resistance}

Malhi \& Farmer (1999) comment that in their clinical experience effective therapy for treatment-resistant depression necessitates enhancement of noradrenergic neurotransmission because of the effect this has on the typical symptoms of severe depression, which they speculate is more likely to lead to treatment resistance. It could seem from their letter that they advocate holding noradrenergic antidepressants in reserve for treatment-resistant depression.
Such an interpretation would be unfortunate as it is probable that much of what is called treatment resistance results from the use of the wrong antidepressant. Roose $e t$ al (1994) showed a substantial superiority for nortriptyline over fluoxetine in patients with melancholia. Melancholia is linked to abnormal response to the dexamethasone suppression test (DST) (Carroll et al, 1981), and some studies have shown a preferential response to noradrenergic antidepressants in patients with an abnormal DST (Fraser, 1983; Kin et al, 1997). The failure of many other studies to replicate that finding is likely to be due to a closer link between DST non-suppression and weight loss or sleep disturbance, than melancholia (Mullen et al, 1986). Nevertheless, no study has shown an advantage for a serotonergic antidepressant over a noradrenergic antidepressant in patients with melancholia, psychosis, or DST nonsuppression.

In recent years, psychiatrists have been exhorted to avoid the dangers of the older (especially tricyclic) antidepressants in favour of the safer selective serotonin reuptake inhibitors (SSRIs). Their greater safety arises from an absence of cardiotoxicity, a lack of cognitive slowing, and minimal effect on blood pressure. Preferential prescription of an SSRI is justified on the basis that there is no evidence that any antidepressant is consistently any more effective than any other antidepressant in double-blind controlled trials.

Although it has not been conclusively demonstrated that noradrenergic drugs are better than serotonergic drugs for severe or melancholic major depression, there is a definite possibility that they are. More importantly, there is no evidence that they are worse than serotonergic drugs. Clinicians should preferentially prescribe a noradrenergic antidepressant for melancholic depression. Those who do so are likely to experience a decreased frequency of treatment-resistant depression among their patients, just as I have over the past 18 years.

Carroll, B. J., Feinberg, M., Greden, J. F., et al (1981) A specific laboratory test for the diagnosis of melancholia. Archives of General Psychiatry, 38, 15-22.

Fraser, A. R. (1983) Choice of antidepressant based on the dexamethasone suppression test. American Journal of Psychiatry, 140, 786-787.

Kin, N. M., Nair, N. P., Amin, M., et al (1997) The dexamethasone suppression test and treatment outcome in elderly depressed patients participating in a placebo-controlled multicentre trial involving 
moclobemide and nortriptyline. Biological Psychiatry, 42 , 925-931.

Malhi, G. S. \& Farmer, A. E. (1999) Drug therapy in treatment-resistant depression (letter). British Journal of Psychiatry, I75, 390-391.

Mullen, P. E., Linsell, C. R. \& Parker, D. (1986)

Influence of sleep disruption and calorie restriction on biological markers for depression. Lancet, ii, 1051-1055.

Roose, S. P., Glassman, A. H., Attia, E., et al (1994) Comparative efficacy of selective serotonin reuptake inhibitors and tricyclics in the treatment of mania. American Journal of Psychiatry, I5I, 1735-1739.

A. R. Fraser Mood Disorders Service, Waitemata, Mental Health Services, Takapuna, New Zealand

\section{Depression and interferon-alpha therapy}

In their case report, McAllister-Williams et al (2000) hypothesise that recurrence of major depression following treatment with interferon-alpha (IFN $\alpha$ ) is related to its capacity to impair serotonin synthesis by inducing enzymes that degrade tryptophan and they cite in vitro evidence in support of this. We suggest that there are other in vivo biological effects of this treatment, which may explain the association of IFN $\alpha$ with depression.

First, it is possible that the pathogenesis of depressive symptoms following treatment with IFN $\alpha$ is related to disturbance of the hypothalamic-pituitary-adrenal (HPA) axis. Overactivity of the HPA axis occurs commonly in people with major depressive disorder (Dinan, 1994), the rates of overactivity increasing with growing severity of depression. There is evidence to suggest that the effects of antidepressants on mood may be brought about by re-equilibration of the HPA axis (Barden et al, 1995). Exogenous IFN $\alpha$ therapy has been found to increase plasma adrenocorticotrophic hormone (ACTH) and serum cortisol in humans (Shimizu et al, 1995). The mechanism, however, does not appear to be a direct one as exogenous IFN $\alpha$ is a polypeptide that does not cross the blood-brain barrier and direct application of IFN $\alpha$ to cultured pituitary cells does not release ACTH. Indirect effects of exogenous IFN $\alpha$ on the HPA axis may occur through activation of endogenous cytokines, specifically interleukin-6 (IL-6) which is known to stimulate release of corticotrophinreleasing factor from rat hypothalamus in vitro. Furthermore, increase in serum IL-6 following in vivo IFN $\alpha$ is positively correlated with the IFN $\alpha$-induced changes in serum cortisol (Shimizu et al, 1995).

Second, the possible effects of IFN $\alpha$ on tryptophan availability to which the authors refer may be a secondary effect of immune system activation. Major depression is associated with an activation of the immune-inflammatory response system, with cell-mediated increases in serum levels of pro-inflammatory cytokines including IL-6. Reduced availability of tryptophan in depression may be a result of this inflammatory response activation (Song et al, 1997). Exogenous IFN $\alpha$ also activates pro-inflammatory cytokines.

Paradigms about the aetiology of major depressive disorder are expanding beyond a narrow monoamine-centred concept. Clearly, stress, either medical or psychological, is important in the aetiology of depression. The major stress axis, the HPA, which is overactive in major depression, is potently activated by both exogenous and endogenous cytokines.

We suggest, therefore, that these biological pathways are important in the pathophysiology of depression during treatment with IFN $\alpha$.

\section{Barden, N., Reul, J. M. \& Holsboer, F. (1995) Do} antidepressants stabilise mood in depression through actions on the hypothalamic-pituitary-adrenal system? Trends in Neuroscience, 18, 6-17.

Dinan, T. G. (1994) Glucocorticoids and the genesis of depressive illness. A psychobiological model. British Journal of Psychiatry, 164, 365-37I.

McAllister-Williams, R. H., Young, A. H. \& Menkes, D. B. (2000) Antidepressant response reversed by interferon (letter). British Journal of Psychiatry, I76, 93.

Shimizu, H., Ohtani, K., Sato, N., et al (1995) Increase in serum interleukin-6, plasma ACTH and serum cortisol levels after systemic interferon- $\alpha$ administration. Endocrine Journal, 42, 55I-556.

Song, C., Lin, A., Bonaccorso, S., et al (1998) The inflammatory response system and the availability of plasma tryptophan in patients with primary sleep disorders and major depression. Journal of Affective Disorders, 49, $211-219$

E. M. Cassidy, V. O'Keane Beaumont Hospital, PO Box 1297, Beaumont Road, Dublin 9, Republic of Ireland

\section{Sluggish economics affect health of Japanese 'business warriors'}

Health among the Japanese people has been faltering since the 'bubble' economy burst in the early 1990s. The consequences of the recession are now visible. A middleaged man committed hara-kiri, a ritual form of suicide often committed in the name of honour. In the past, samurai were willing to kill themselves to maintain the oie (the family which governed the territory inherited from the ancestor). The man appealed, at the expense of his life, to the company for which he had worked for decades, one of the most successful companies in Japan.

To survive the competitive business world, many Japanese companies have now embarked upon restructuring. It is those middle-age men, who contributed to the economic success of Japan since the Second World War, who are now, ironically, the target for restructuring. They have devoted almost all of their lives and often sacrificed their own family life for their companies. People have had the aisha-seisin (a deep spiritual attachment to their own company) exactly akin to that held by the samurai for the oie. The man who commited hara-kiri had trusted the company and believed that the company would not abandon the business warriors. He killed himself when he felt betrayed by the company.

There is evidence that the poor economic performance of Japanese business has affected the health of the nation. The number of deaths from suicide reached 31734 (25.2 per 100000 people) in 1998 (Statistical Information, Department of Health, Japan; further information available from the first author upon request); Japan's highest rate since statistics were first recorded in 1899. The rate of suicide has also risen after the end of the economic 'bubble', notably for middle-aged men, approaching 50 per 100000 people (Taniguchi et al, 1998). An increase in the suicide rate, especially among middle-aged men, affected the estimate of life expectancy downward; as a consequence, the gap in expected longevity between men and women in Japan has become wider (6.85 years: Department of Health, Japan, August 6, 1999 (further information available from the first author upon request)).

Karoshi (early death due to overwork) (Lawlis, 1995) is also a result of aisha-seisin. These deaths can be avoided. People should realise that a strong worker-company bond and becoming a 'business warrior' is hazardous to health.

Lawlis, G. F. (1995) Alternative therapies in Japan: a prototype for conquering 'karoshi' and stress. Alternative Therapies in Health and Medicine, I, 28-29. 